\title{
La Teoría de las Constantes Jurídicas y la Historia del Derecho Peruano
}

\author{
por el Dr. J. VICENTE UGARTE DEL PINO *
}

Existe una inevitable idea sobre la Historia tel Derecho, que nos induce a concebir'a como el relato externo y pormenorizado de la evolución jurídica de un pueblo. Creemos que esto es natural que suceda por cuanto la imagen de la Historia ha dejado en nosotros ancestral huella, es decir de la Historia concebida tradicionalmente desde la época clásica. Pero creemos que entre la breve Historia del Derecho Romano de Pomponio a nuestros dias, es tiempo suficiente para que tengamos una nueva concepción de la Historia en general y de la del Derecho en especial. Lo difícil es conseguir que los juristas reparen en la importancia vital que en la estructura de un Estado, tiene el conocimiento de la intrahistoria juridica del mismo, y lo cierto del caso es, que siempre los a ficionados a estos estudios tenemos que estar dando explicaciones a cada paso, como --en su tiempo- el jurista Gayo, por haber distraido el tiempo con explicaciones de tipo Histórico al efectuar la exposición de la "Ley de las Doce Tablas".

Nosotros concebimos la Historia del Derecho, no como un simple Catálogo o Almanaque jurídico, sino como un sistema o modo de entender al hombre y su obra en el campo del Derecho, no por vía abstracta e intempural sino por la observación de lo singu'ar y de lo sucesivo, de aquello que está ubicado dentio de un punto determinado del tiempo. Pero, por otra parte, estamos igualmente empezando a ver más y más no sólo a los indiv'duos aislados s'no también a los hombres como partes de ciertos grupos que han desarrolado un estilo particular.

Este estilo particular o manera peculiar de concebir la vida y las relaciones interindividuales es lo que constituye en cierto modo la dogmática o concepción del mundo en un grupo determinado. Indudablemente que esta dogmática, no es sino la resultante del influjo de algunos espiritus selectos

* Abogado. - Catedrático de Historia del Derecho Peruano en la Pontificia Universidad Católica y en la Universidad Nacional Mayor de San Marcos. 
dentro del grupo, inf'ujo que solo se completa dentro de la sociedad, convirtiendo su vida y su obra en algo más permanente que sus individualidades. Esto que algunos llaman "co-presencia", o relación interindividual es la que va creando ciertas relaciones esenciales que con el devenir forma una serie de categorias, que no son otra cosa que la dogmática, o manera de captar la vida, de entender el mundo y lógicamente de moverse dentro de él, dentro de su rea'idad socio-histórica.

Es asi pues como la Historia del Derecho, no sólo nos proporciona una serie sucesiva de cuerpos juridicos, sino un panorama mucho más útil e interesante constituido por cuerpos históricos los que observados en sus grandes perspectivas, como cuando uno contempla un cuadro o una obra de arte, en que no interesan los detalles sino el conjunto, en esta observación, nosotros extraemos el denominador común de los fenómenos reiterados, dentro de una selección de hechos e ideas, dentro de ciertos límites de tiempo y espacio. $\mathrm{Y}$ asi es como se pueden establecer determinadas constantes juridicas en el proceso evolutivo de un pueblo. Constantes que pueden estar conformes con el Derecho de nuestra época, simpiemente fuera de él e inclusive contra él, como sucede con las simples costumbres. Y aqui tenemos que aclarar, que las constantes jurídicas, no implican una confusión con la costumbre de un pueblo, ya que nosotros hemos estado hablando de las relaciones "inter-individuales" del hombre como sujeto histórico, las mismas que so'o se dan dentro de estructuras o personas jurídicas como las asociaciones, el Estado, convenios, etc. actos que caen dentro del puro dominio del derecho y cuya reiteración nos interesa determinar dentro de la visión total de cada época. Esto, es pues de mucha más importancia que la concepción historiográfica común, que va de la mano con el diar:o acontecer. En esto radica creemos la supremacia de esta manera de concebir la Historia del Derecho, en que solo repara en 'as grandes perspectivas y en las líneas generales de la evolución jurídica de un pueblo, desechando lo anecdótico.

Por este camino llegamos inclusive al conocimiento casi perfecto de la concepción del mundo o dogmát:ca de una época determinada, a tal punto en que cari ya no ros es preciso que nos digan quien fue el autor del "Epitome de 'a Biblioteca Occidental" o de "La Política Indiana", para que sepamos a que tiempo perienecen, al igual que no necesitamos conocer a ios creadores del arte egipcio o gótico, para saber la cultura y la época a que pertenecen. La obra de Jean Domat, no !a cencebiriamos en nuestro tiempo, asi como no concibe Leclercq los versos de Victor Hugo en el Siglo XVII. $Y$ aquí hay una nota interesante que refuerza nuestra posición dentro de le Historia del Derecho.

$Y$ es la de que el hombre dificilmente puede escapar a la dogmática juridica de su tiempo. Ei puede creerse libre de pensar y escribir e inclusive legislar como Vidaurre, en su tiempo, pero en realidad no lo es, porque la manera como lo hace, depende del pais y de la época en que ha nacido. En re:slidad, hay una fuerza que le domina, que es más duradera que él mismo, y sobrepasa cada vez más las fuerzas creadoras del individuo. 
Por eso con toda razón don José Ortega y Gasset, afirmaba en su libro: "La Historia como sistema", que si un hombre se formulara la pregunta por qué su vida es así y no de otro modo, le aparecerian no pocos detalles originados por un incomprensible azar. Pero -añadia - "las grandes lineas de su realidad le parecerán perfectamente comprensibles cuando vea que es él así porque, en definitiva, es asi la sociedad -el hombre colectivo- donde vive" y, a su vez, el modo de ser de ésta quedará esclarecido - prósigueal "descubrir dentro de él lo que esa sociedad fué, creyó, sintió, prefirió. antes $y$, asi sucesivamente".

Aqui Ortega nos lanza a una introspección en la que el hombre verâ en su propio e instantáneo hoy, el "escorzo de todo el pasado humano". E indudablemente asi lo creemos, y nunca podremos explizarnos lo actual sino como resultado de fuerzas actuantes que vienen de atrás, del pasado inmediato pero que eslabonadas nos llevarán al pasado más remoto, resultando asi la Historia un sistema -el sistema de las experiencias humanas- como la definió Ortega.

Partiendo pues de estas bases, es que podemos nosotros hablar de la "Teoria de las constantes jurídicas", dentro de la Historia del Derecho en general, pero del Peruano en especial. Ella corre paralela y como resu'tado del estudio de las lineas de tendencia en la evolución juridica de un pueblo. ya que al efectuar la introspección resaltan no sólo las tendencias o vocación por ciertas Instituciones, sino la reiteración frente a determinadas circunstancias de un pueblo.

En esto encontramos nosotros la máxima importancia de la Historia del Derecho: la de poder otorgar a los legisladores un cuadro exacto de como se ha producido el estado actual de cosas, las razones auténticas, por las que un país, pongamos el Perú, se ha constituido tal cual se encuentra ante nuestros ojos y no de otra manera. En esta forma las leyes podrán dictarse más técnicamente conformes con el espiritu colectivo del Perú, y no volveremos a caer en el desprecio por la ley. fruto de la inadecuación de ésta con las tendencias populares o sociales. Así pues las Cátedras de Historia del Derecho, están llamadas a tener una importancia de primer orden y a convertirse en verdaderos laboratorios, donde se investigue el hecho juridico de un pueblo para establecer el nexo entre el mismo y la realidad social a través del tiempo, deduciéndose asi, de verdades comprobadas, y no de meras especulaciones hipotéticas, las leyes de un pueblo. Prắcticamente, se podrian establecer gráficas y cuadros de constantes juridicas y delinear las tendencias de nuestro pueblo sobre determinadas categorias de orden legal.

Indudablemente que estas ideas y esta forma de concebir la Historia del Derecho, está más de acuerdo en definitiva con lo que pretendieron Savigni y los miembros de la llamada "Escuela Histórica del Derecho", el Siglo $\mathrm{XIX}$, por cuanto ellos en medio de las tremendas convu'siones politicas que se derivaron de la revolución en Francia, trataron de dotar a su patria - Alemania- de un derecho estable y al margen de los vaivenes de la realidad colectiva. 
Con gran sentido de responsabilidad, ellos pensaron que no era posible que los pueblos tuvieran que sufrir los efectos de la moda juridica o los de la imposición extranjera, de espaldas a su devenir histórico. Y lógicamente también tenia que buscarse la seguridad a la que el Derecho aspira, rastreando los principios a los cuales se conforma la evolución de la experiencia de un grupo humano. Asi se generó en Europa Central, el movimiento en torno a la obra: "De la vocación de nuestro Sig'o para la legislación y para la ciencia del Derecho", publicada por Federico von Savigni, en 1814, y en cuya linea destacaron dentro de la revista de la Escuela Histórica, figuras como Eichorn, Cösschen y Otto Gierke.

Precisamente de este último, es la frase: "nos parrece evidente de suyo, el que la inteligencia cientifica del Derecho sólo será posib'e partiendo de su historia". Esta idea y la valorización del Derecho consuetudinario fueron sin duda alguna dos logrados frutos de la Escuela Histórica, conjuntamente con la importancia del estudio de la continuidad histórica en la formación de' Derecho, que demuestra que el Derecho del presente tiene tanta más vida cuanto más sólidamente arraiga en el Derecho del pasado.

Finalmente, creemos sinceramente que el sorvicio de esta manera de concebir la Historia del Derecho, puede prestar a países como el Perú, de variada conformación sociológica es muy útil, por cuanto aquí no podríamos generalizar en el dominio de ciertas leyes específicas, desde que no podemos aplicar el mismo rasero a todos los peruanos, pues no sólo cabe la diferenciación elemental de ciudad y campo, sino que hay que tener en cuenta la supervivencia de formas de vivir y entender la vida en algunos lugares de la sierra - muy numerosos-, que solo podremos adaptar mediante una cuidadosa y progresiva labor cultural en la que no debemos olvidar el lastre de constantes juridicas de tal vez algunos miles de años, e instituciones que han sobrevivido a los Incas, los Virreyes y toda nuestra Historia republicana. 